Original Article - Clinical Science

\title{
The future burden of vision loss in Australia: projections from the National Eye Health Survey
}

J oshua Foreman PhD, ${ }^{1,2}$ Stuart Keel PhD, ${ }^{1,2}$ Myra McGuiness PhD, ${ }^{1}$ Danny Liew PhD, ${ }^{3}$ Peter van Wigngaarden FRANZCO, ${ }^{1,2}$ Hugh R. Taylor FRANZCO ${ }^{4}$ and Mohamed Dirani $\mathrm{PhD}^{1,5}$

${ }^{1}$ Centre for Eye Research Australia, Royal Victorian Eye \& Ear Hospital, Melbourne, Australia, ${ }^{2}$ Ophthalmology, University of Melbourne, Department of Surgery, Melbourne, Australia, ${ }^{3}$ School of Population Health and Preventive Medicine, Monash University, Melbourne, Australia, 4 Indigenous Eye Health Unit, Melbourne School of Population and Global Health, The University of Melbourne, Melbourne, Australia, ${ }^{5}$ Singapore Eye Research Institute, Singapore National Eye Centre, Singapore

Correspondence: Joshua Foreman, Centre for Eye Research Australia, Level 1, 32 Gisborne Street, East Melbourne, Victoria, Australia 3002

Email: $\quad$ foremanj@unimelb.edu.au

Short running title: Projections of vision loss in Australia Received 9 J anuary 2020; accepted 24 April 2020 Funding sources / Financial disclosure: Australian Government Department of Health, the Peggy and Leslie Cranbourne Foundation and Novartis Pharmaceuticals Conflict of interest: None

This is the author manuscript accepted for publication and has undergone full peer review but has not been through the copyediting, typesetting, pagination and proofreading process, which may lead to differences between this version and the Version of Record. Please cite this article as doi: $10.1111 /$ ceo.13776

This article is protected by copyright. All rights reserved. 


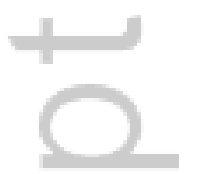

4 


\section{ABSTRACT}

Importance: Projections of Australia's future burden of vision loss will inform eye health service delivery.

Background: This study aimed to forecast bilateral vision loss in Australia from 20202050.

Design: Population-based survey

Participants: Indigenous and non-Indigenous Australians $(n=4,253)$ aged $\geq 50$ years from the National Eye Health Survey (NEHS, 2015-2016).

Methods: Using the age-and-sex-stratified prevalence of vision loss (better eye visual acuity $<6 / 12$ ) from the NEHS, the prevalence of and number of people aged $\geq 50$ years with vision loss were forecast to 2050 using Australian census projections.

Main outcome measure: Prevalence of, and number of Australians with, vision loss from 2020-2050.

Results: The prevalence of vision loss is predicted to increase from $6.7 \%$ to $7.5 \%$ by 2050. Owing to population dynamics, the estimated number of Australians $\geq 50$ years old with vision loss will nearly double from 532,386 in 2016 to 1,015,021 in 2050. The greatest increase in vision loss is expected to occur in those aged $\geq 80$ years (2.6-fold, $2016=144,240 ; 2050=376,296)$. The number of people with uncorrected refractive error is projected to increase 1.7-fold, from 331,914 in 2016 to 578,969 in 2050.

Conclusions and Relevance: Due to population growth and ageing, the future burden of vision loss in Australia is likely to increase, but the magnitude of this change is uncertain due to a lack of available data on some relevant input variables. Nonetheless, efforts are required to ensure early detection and treatment of major eye conditions, particularly treatable conditions such as uncorrected refractive error and cataract.

Keywords: Projections, vision loss, National Eye Health Survey 


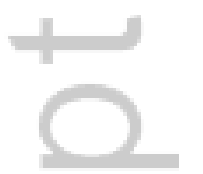

4 


\section{I NTRODUCTI ON}

Globally, the number of people with bilateral vision loss has been predicted to almost triple from 253 million in 2015 to 702 million in 2050, owing to the growth and ageing of the world's population. ${ }^{1}$ Given that vision loss is already the third leading cause of disability worldwide ${ }^{2}$ and that it costs the global economy over USD 2 trillion annually, ${ }^{3}$ this projected rise represents a significant economic and public health concern. To optimise the planning of targeted eye healthcare programmes that will mitigate the projected rise in vision loss, policy-makers in each country require country-specific predictions of the potential future magnitude of vision loss based on reliable population data.

Australia has benefitted from significant efforts to reduce the national burden of vision loss in recent years, with a number of policies and programmes being implemented including the 'National framework for action to promote eye health and prevent avoidable blindness and vision loss'. ${ }^{4}$ Despite noteworthy progress, important deficits in service delivery remain, particularly among Australians residing in non-metropolitan areas $^{5}$ and Australia's Indigenous population which continues to have a prevalence of vision loss that is three times higher than the non-Indigenous population. ${ }^{6}$ These deficits, coupled with expected population growth and ageing, portend a dramatic rise in the future prevalence of vision loss in Australia. Indeed, the number of Australians aged 50 years or older, in whom $85 \%$ of all vision loss occurs, ${ }^{7}$ is expected to increase by almost $50 \%$ in the next twenty years to 11.2 million. ${ }^{8}$ Projected increases in the prevalence of both myopia ${ }^{9}$ and diabetes ${ }^{10}$ (and hence diabetic retinopathy) may further exacerbate the rise in vision loss in Australia.

Forecasting data are therefore required to predict Australia's future eyecare needs. Projections by Taylor and colleagues (2005) estimated the burden of vision loss in Australia from 2004- 2024 on the basis of pooled data from two state-based surveys, the Melbourne Visual Impairment Project (VIP) and the Blue Mountains Eye Study 
(BMES). ${ }^{11}$ However, changes in the epidemiology of vision loss since the completion of those studies, ${ }^{12,13}$ coupled with significant changes in key population parameters, ${ }^{8}$ highlight the need for projections based on current and nationally-representative data. Data on the nationwide prevalence of bilateral vision loss in Australian older adults were provided for the first time by the National Eye Health Survey (NEHS) in 2016. ${ }^{14}$ Using these prevalence estimates together with up-to-date population projections from the Australian Bureau of Statistics (ABS) that incorporate future changes in relevant demographic factors, we sought to forecast the number of Australians aged 50 years and older with bilateral vision loss from 2020 to 2050.

\section{METHODS}

\subsection{The National Eye Health Survey}

The NEHS (March 2015-April 2016) was a nationwide population-based survey of the prevalence and causes of vision loss among non-Indigenous Australians aged 50 years and older and Indigenous Australians aged 40 years and older. The sampling, recruitment and clinical examination methodology of the NEHS has been published previously. ${ }^{15,16}$ In brief, drawing on 2011 Census data, ${ }^{8}$ the survey utilised multistage random-cluster sampling to select 30 population clusters of 150 participants ( 100 nonIndigenous and 50 Indigenous residents per sampling site) from all levels of geographic remoteness, and participants were recruited door-to-door. Participants underwent an interviewer-administered questionnaire and an eye examination which consisted of visual acuity assessment (with pinhole and auto-refraction for those with presenting visual acuity [PVA] $<6 / 12$ in one or both eyes), anterior segment examination, perimetry, fundus photography and intraocular pressure assessment. ${ }^{16}$ Bilateral vision loss was defined in the NEHS as PVA $<6 / 12$ in the better seeing eye. Uncorrected or under-corrected refractive error was assigned as the main cause of vision loss when visual acuity improved to $\geq 6 / 12$ in one or both eyes with pinhole or 
refractive correction. For all other cases, the main cause of vision loss was determined by two independent ophthalmologists who reviewed questionnaire responses and examination results to identify the condition most likely to account for vision loss. Disagreements were adjudicated by a third ophthalmologist. When multiple disorders were identified, the most clinically significant condition was determined to be the primary cause.

Ethics approval was obtained from the Royal Victorian Eye and Ear Hospital (RVEEH) Human Research Ethics Committee (HREC-14/1199H) and additional ethical approvals were obtained at the State level to conduct research within Indigenous communities. Each participant provided written consent after being informed of the nature of the study. The study was conducted in accordance with the tenets of the Declaration of Helsinki.

\subsection{Population projections}

Australian population projections for the years 2020 to 2050 were provided by the ABS. Projections were stratified by sex, geographic remoteness (major city, inner and outer regional, or remote and very remote) and age group (50-59, 60-69, 70-79 and $\geq 80$ years, Table 1). ${ }^{17}$ These projections were derived from the 2016 Australian Census of Population and Housing and included assumptions about expected changes in rates of fertility, mortality and migration trends in the Australian population. ${ }^{18}$ All Australian states and territories (including "Other Territories") were included.

\subsection{Statistical analysis}

The prevalence of vision loss among Australians aged 50 years and older at the time of the NEHS was estimated using post-stratification to the 2016 population structure (stratified according to sex, Indigenous status, remoteness and age) in addition to survey weights which were derived separately for Indigenous and non-Indigenous participants according to study site. The 2016 population structure was extracted from 
the ABS TableBuilder, stratified by sex, Indigenous status (non-Indigenous or not stated vs Aboriginal, Torres Strait Islander or both Aboriginal and Torres Strait Islander), remoteness and age and compared to the demographic structure of the NEHS sample using Pearson's $\chi^{2}$ test to identify potential sources of unrepresentativeness. ${ }^{19}$

The number of people with vision loss was then estimated for each year from 2020 to 2050 using direct standardisation from the NEHS sample to the projected population structure according to age, sex and remoteness. Up-to-date ABS projections of population numbers stratified by Indigenous status were not available at the time of analysis. Therefore, the projected proportion of Indigenous Australians in each stratum (defined by age, sex and remoteness area) was held constant over time. The projected prevalence of vision loss was then estimated as the projected number with vision loss divided by the total Australian population aged 50 years and over projected for each timepoint in 5-year intervals between 2020 and 2050. Because projected prevalence was estimated assuming no change in the proportion of Indigenous Australians within the population, the distribution of demographic characteristics (age, sex, educational attainment, remoteness and place of birth) was compared between Indigenous and non-Indigenous NEHS participants using Pearson's $\chi^{2}$ test to investigate potential sources of bias.

Numbers of Australians projected to have vision loss from the two leading causes of vision loss - uncorrected refractive error and cataract - were calculated separately for each 5-year interval. Owing to the comparatively small sample of NEHS participants with vision loss from other eye diseases such as glaucoma, age-related macular degeneration, diabetic retinopathy and loss frequently blinding diseases, the numbers of those projected to have vision loss from 'other causes' (i.e., causes other than cataract or uncorrected/undercorrected refractive error) were combined and calculated for each 5-year interval. 


\section{RESULTS}

\subsection{Demographic characteristics of the NEHS sample}

A total of 4,836 Australians participated in the NEHS, of whom 4,253 (88\%) were eligible for inclusion in this analysis based on age criteria ( 583 Indigenous participants aged 40-49 excluded). Participants were aged 50 to 89 years (median 64, interquartile range $57-71$ ) and $54.8 \%$ were female. The distribution of several demographics differed between the NEHS participants and the 2016 Australian population. The proportion of Indigenous males and the level of education among Indigenous participants were lower in the NEHS than in the target Australian population $(p<0.001)$. Compared to the target population, non-Indigenous NEHS participants were less likely to have been born outside of Oceania or Europe and had a lower level of education and there was a smaller proportion of NEHS participants within the youngest age group ( $50-59$ years) ( $p<0.001$ for each).

\subsection{Prevalence of vision loss in the NEHS}

The estimated baseline (2016) nationwide prevalence of bilateral vision loss among non-Indigenous Australians and Indigenous Australians aged 50 years or older was 6.6\% (95\% confidence interval [Cl]: $5.5 \%-8.0 \%)$ and $13.3 \%(95 \% \mathrm{Cl}: 10.9 \%-$ $16.2 \%$ ), respectively (Table 2 ). The overall prevalence of bilateral vision loss in Australians aged 50 years and older, including both Indigenous and non-Indigenous Australians, was $6.7 \%$ (95\% Cl 5.6\%-9.4\%). There prevalence of vision loss was $5.2 \%$ in those aged $<60$ years, and although the prevalence decreased slightly amongst those aged $60-69$ years to $4.1 \%$, it increased to $8.4 \%$ in $70-79$-year-olds and $15.2 \%$ in those aged $\geq 80$ years. 


\subsection{The projected number of Australians aged 50 years and over with bilateral vision loss from 2020-2050}

ABS projections suggest there will be a 1.7-fold increase in the number of Australians aged 50 years and over between 2016 and 2050. This is compared to a 1.4-fold increase in the Australian population overall. ${ }^{20}$ Accounting for expected changes in Australia's age, sex and remoteness structure, we estimate that by the year 2050 the prevalence of vision loss amongst the Australian population aged 50 years and older will increase to $7.5 \%$ (Figure 1). Accordingly it is estimated that the number of Australians aged 50 years and over with bilateral vision loss will nearly double from 532,386 in 2016 to 1,015,021 in 2050 (Table 3). The greatest increase in the number of people with vision loss is expected to occur in those aged 80 years and older (2.6fold, $2016=144,240$ people; $2050=376,296$ people), followed by $70-79$ years (1.9fold), $60-69$ years ( 1.5 -fold) and $50-59$ years ( 1.5 -fold). Females with vision loss are expected to outnumber males by approximately $3.8 \%$ in 2050 .

The number of people with uncorrected refractive error is projected to increase 1.7fold, from 331,914 in 2016 to 578,969 in 2050, while, during the same period, the number of people with vision loss due to cataract is anticipated to increase as much as 2.1-fold (Table 4). The number of cases of vision loss from all other causes, including age-related macular degeneration, glaucoma, diabetic retinopathy and other less common causes of vision is expected to increase 2.2 -fold to almost 300,000 by the year 2050.

\section{DISCUSSION}

A paucity of estimates of the future burden of bilateral vision loss in Australia has hindered efforts to plan for Australia's future eye care needs. Using the first national estimates of vision loss combined with population projection data, this paper provides 30 -year projections of vision loss amongst Australians aged 50 years and older. These 
data suggest that the number of Australian adults in this age group with vision loss will almost double by the year 2050, which will likely have major health and economic implications.

Future planning will need to consider increased costs driven by greater demand on national health care expenditure, including Medicare subsidies for eyecare consultations, cataract surgery and therapeutics for common retinal diseases, disability support pensions and low vision rehabilitation services. Australia is predicted to have a surplus of optometric senvice providers, at least until the year 2036, and simply increasing the optometric workforce will therefore be unlikely to be sufficient to address the fact that half of the 1 million cases of vision loss will be due to underor uncorrected refractive error. ${ }^{21}$ Rather, new senvice delivery models that more appropriately distribute the eye health workforce will be required to tackle the geographic heterogeneity of vision loss, particularly in remote and Indigenous communities. ${ }^{22}$ Furthermore, vision loss has a strong impact on the utilisation of community support services and nursing home placement, which will necessitate reevaluation of the capacity for current services to keep up with demand. Estimates from this study may serve as a starting point for policy-makers to plan for the future eye health care needs of Australians.

The ageing of Australia's population is related to two key factors. Following a peak in family sizes during the baby boomer generation (1946-1964) families are, on average, having fewer children and the proportion of younger Australians is therefore declining. The number of Australians aged 65 and over is expected to increase from around $15 \%$ of the total population in 2017 to $25 \%$ in $2050 .{ }^{23}$ Secondly, Australia's life expectancy is increasing - on average Australians lived 10 years longer in 2018 than they did 30 years ago. ${ }^{24}$ Due to these ageing effects, we estimate that the number of Australian adults with vision loss will almost double by 2050 . While a $1 \%$ increase in prevalence may seem modest, when considered in light of projected changes in population dynamics, we predict that over 1 million Australian adults could have vision loss by 
the year 2050. The greatest increase in the absolute number of Australians with vision loss is expected between 2020 and 2030, increasing by 39\%, which is substantially higher than the $14-20 \%$ increase expected in subsequent decades. This rapid escalation over the coming decade is a direct result of further cohorts of baby boomers turning 65 years or older and thus being at a significantly greater risk of vision loss.

When compared to current population-based data from the NEHS collected between 2015 and 2016, previous predictions for the same period based on the BMES and VIP data over-estimated the expected number of people with vision loss by approximately 20\% (2020 estimates: 589,890 [NEHS] vs. 716,400 [combined BMES and VIP]). ${ }^{11}$ While this may partly reflect improvements in eye care utilisation and treatment coverage of ocular disease in Australia over the past 30 years, ${ }^{25-28}$ we suspect that these differences may also be explained by the utilisation of more representative model inputs for vision loss in the present study combined with our use of contemporary population data that closely resembles the current Australian population structure.

Our projections for vision loss in Australia are well aligned with those from a recent study in the United States ${ }^{29}$ in terms of the rate of increase over the coming 30 years (1.9-fold in Australia vs. 2.1-fold in the United States) and the projected gender disparity (i.e. females with vision loss will outnumber males). This is likely to reflect strong parallels between the population structure of Australia and the US with regards to mean age (Australia $=37.3$ years; US $=37.6$ years), female life expectancy ( $\sim 4$ years longer than males in Australia and the US), and proportion of people aged 65 years and over (15\% for both countries). ${ }^{30}$

The strengths of this study include the use of contemporary national estimates of vision loss, stratified by remoteness and Indigenous status, to account for differences in the prevalence of vision loss amongst population sub-groups in Australia. In addition, unlike previous projections that assumed the overall prevalence of vision loss would remain static over time, ${ }^{11}$ we adjusted the prevalence based on changes 
forecast by the Australian Government in the regional, sex and age structure of the population.

Despite this, the findings of this study should be considered in the context of several key limitations. Because the proportion of Indigenous Australians in each stratum was held constant over time (due the lack of stratification by the ABS according to Indigenous status), the number of people with vision loss may have been underrepresented in this study. Australia's I ndigenous population is growing proportionately faster than the non-Indigenous population and is experiencing an increase in life expectancy. ${ }^{31}$ Given that vision loss is more prevalent in Indigenous Australians, particularly amongst those who are older, the prevalence and total case numbers of vision loss in the Indigenous community may increase more rapidly than among nonIndigenous Australians, contributing to a higher overall number of cases. However, because Indigenous Australians comprise a small percentage of the population, this effect is not likely to be pronounced.

An additional limitation is that, while some data inputs were nationally-applicable and highly appropriate for this analysis, including the baseline prevalence of vision loss and the projected population growth and ageing, our model did not account for the potential modulating effect of other model inputs on the prevalence of vision loss. For example, because $75-80 \%$ of vision loss in Australia is readily reversible or preventable with spectacles, cataract surgery and early treatment of diabetic retinopathy, ${ }^{6}$ treatment coverage rates for avoidable causes of vision loss may be expected to improve with better targeting of eye healthcare service delivery programs. Indeed, interventions that have recently been implemented may soon have downstream attenuating effects on the prevalence of vision loss, such as the national rollout of the KeepSight diabetic retinopathy screening programme, ${ }^{32}$ the allocation of $\$ 33.8$ million in Medicare rebates to general practitioners for non-mydriatic fundus photography in diabetic patients ${ }^{33}$ and several Government initiatives to improve access to spectacles. ${ }^{34}$ The magnitude of the influence of these variables on the overall future 
prevalence of vision loss is unknown partly because the future burden of diabetes in Australia and modulating effects of other variables that are unaccounted for are presently difficult to predict.

Furthermore, there are likely to be unforeseen technological breakthroughs within the next 30 years that will result in earlier detection and improved treatment for common eye diseases such as age-related macular degeneration and glaucoma. Thus, the present study may over-estimate the prevalence of vision loss in the coming decades. On the other hand, other factors may increase Australia's prevalence of vision loss, including the current myopia crisis (which may affect up to $55 \%$ of the population of Australasia by 2050) ${ }^{9}$ and the expected increase in the prevalence of diabetes ${ }^{10}$ however recent Australian Government data indicate a plateau in diabetes prevalence in the past 5 years, ${ }^{35}$ and further data are required to permit accurate projections to resolve this discrepancy. Nevertheless, the often contradictory or entirely absent literature regarding projections for and complex interactions between these variables has rendered their modulating effect on projections of vision loss unquantifiable and they were therefore excluded from analysis.

These data provide an estimate of the future burden of vision loss amongst Australian adults. This increased burden is likely to have a profound economic impact on health care systems, particularly in the coming decade when the Australian baby boomers reach an age where vision loss is most prevalent. While the projections presented here were derived from nationally-representative data on the prevalence of vision loss as well as reliable Government population projection data, the exclusion of certain input variables which might have modulated these projections necessitates cautious inference about their accuracy. Nontehless, if Australia is to address the the burden of vision loss that is expected based on these projections, innovative approaches for early detection and timely treatment of common causes of vision loss are required, and the effectiveness of these eye care interventions should be monitored and evaluated through regular follow-up and surveillance. 


\section{Acknowledgements}

The Centre for Eye Research Australia and Vision 2020 Australia wish to recognise the contributions of all the NEHS project steering committee members (Professor Hugh Taylor, Dr Peter van Wijngaarden, J ennifer Gersbeck, Dr J ason Agostino, Anna Morse, Sharon Bentley, Robyn Weinberg, Christine Black, Genevieve Quilty, Louis Young and Rhonda Stilling) and the core Centre for Eye Research Australia research team who assisted with the survey field work (Pei Ying Lee, Rosamond Gilden, Larissa Andersen, Benny Phanthakesone, Celestina Pham, Alison Schokman, Megan Jackson, Hiba Wehbe, J ohn Komser and Cayley Bush). Furthermore, we would like to acknowledge the overwhelming support from all collaborating Indigenous organisations who assisted with the implementation of the survey, and the Indigenous health workers and volunteers in each survey site who contributed to the field work. 


\section{REFERENCES}

1. Bourne RRA, Flaxman SR, Braithwaite T, et al. Magnitude, temporal trends, and projections of the global prevalence of blindness and distance and near vision impairment: a systematic review and meta-analysis. Lancet Glob Health. 2017;5(9): e888-e897.

2. Disease GBD, Injury I, Prevalence C. Global, regional, and national incidence, prevalence, and years lived with disability for 310 diseases and injuries, 19902015: a systematic analysis for the Global Burden of Disease Study 2015. Lancet. 2016; 388(10053):1545-1602.

3. Access Economics - prepared for AMD Alliance International. The Global economic cost of visual impairment. 2010.

4. Commonwealth of Australia. National Framework for Action to Promote Eye Health and Prevent Avoidable Blindness and Vision Loss. In. Canberra2005.

5. Foreman J, Xie J, Keel S, Taylor HR, Dirani M. Utilization of eye health-care services in Australia: the National Eye Health Survey. Clin Exp Ophthalmol. 2018;46(3):213-221.

6. Foreman J, Xie J, Keel S, et al. The Prevalence and Causes of Vision Loss in Indigenous and Non-Indigenous Australians: The National Eye Health Survey. Ophthalmology. 2017; 124(12): 1743-1752.

7. WHO. Universal eye health: a global action plan 2014-19. 2013; http://www.who.int/blindness/AP2014_19_English.pdf?ua=1 (accessed Sep 2016).

8. ABS. Australian Statistical Geography Standard (ASGS). 2014;

http://www.abs.gov.au/websitedbs/D3310114.nsf/home/Australian+Statistical +Geography+Standard+(ASGS). 
9. Holden BA, Fricke TR, Wilson DA, et al. Global Prevalence of Myopia and High Myopia and Temporal Trends from 2000 through 2050. Ophthalmology. 2016;123(5): 1036-1042.

10. Magliano DJ, Shaw JE, Shortreed SM, et al. Lifetime risk and projected population prevalence of diabetes. Diabetologia. 2008;51(12):2179-2186.

11. Taylor HR, Keeffe JE, Vu HT, et al. Vision loss in Australia. Med/ Aust. 2005; 182(11):565-568.

12. Foran S, Mitchell P, Wang JJ. Five-year change in visual acuity and incidence of visual impairment: the Blue Mountains Eye Study. Ophthalmology. 2003; 110(1):41-50.

13. Dimitrov PN, Mukesh BN, McCarty CA, Taylor HR. Five-year incidence of bilateral cause-specific visual impairment in the Melbourne Visual I mpairment Project. Invest Ophthalmo/ Vis Sci. 2003;44(12):5075-5081.

14. Foreman J, Xie J, Keel S, et al. The Prevalence and Causes of Vision Loss in Indigenous and Non-Indigenous Australians: The National Eye Health Survey. Ophthalmology. 2017.

15. Foreman J, Keel S, Dunn R, van Wijngaarden P, Taylor HR, Dirani M. Sampling methodology and site selection in the National Eye Health Survey: an Australian population-based prevalence study. Clin Exp Ophthalmol. 2016.

16. Foreman J, Keel S, van Wijngaarden P, Taylor HR, Dirani M. Recruitment and Testing Protocol in the National Eye Health Survey: A Population-Based Eye Study in Australia. Ophthalmic Epidemiol. 2017:1-11.

17. ABS. Population Projections, Australia, 2017 (base) - 2066 - cat. no. 3222.0. In. viewed 25 February 2019, https://www.abs.gov.au 2018.

18. ABS. Demographic Estimates and Projections: Concepts, Sources and Methods, 1999, cat. no. 3228.0. In. viewed 25 February 2019, https://www.abs.gov.au 1999. 
19. ABS. Census TableBuilder. In. accessed 15 J anuary 2019, http://www.abs.gov.au 2019.

20. ABS. Census of Population and Housing: Reflecting Australia - Stories from the Census, 2016 2016. Accessed 5th of March, 2019.

21. Healy E, Kiely PM, Arunachalam D. Optometric supply and demand in Australia: 2011-2036. Clin Exp Optom. 2015; 98(3):273-282.

22. Kiely PM, Chakman J. Optometric practice in Australian Standard Geographical Classification--Remoteness Areas in Australia, 2010. Clin Exp Optom. 2011;94(5):468-477.

23. ABS. Australian historical population statistics, 2014. ABS cat. no. 3105.0.65.001. In.

https://www.abs.gov.au/ausstats/abs@.nsf/mf/3105.0.65.0012014.

24. AlHW. Deaths in Aistralia. 2018. Accessed 5th March, 2019.

25. Foreman J, Keel S, Dirani M. Adherence to diabetic eye examination guidelines in Australia: the National Eye Health Survey. Med/ Aust. 2018;208(2): 97.

26. Foreman J, Xie J, Keel S, Taylor HR, Dirani M. Treatment coverage rates for refractive error in the National Eye Health survey. PLOS One. 2017;12(4):e0175353.

27. Foreman J, Xie J, Keel S, Taylor HR, Dirani M. Utilization of eye health-care services in Australia: the National Eye Health Survey. Clinical \& experimental ophthalmology. 2017.

28. Foreman J, Xie J, Keel S, et al. Cataract surgery coverage rates for Indigenous and non-Indigenous Australians: the National Eye Health Survey. MedJ Aust. 2017;207(6):256-261.

29. Varma R, Vajaranant TS, Burkemper B, et al. Visual Impairment and Blindness in Adults in the United States: Demographic and Geographic Variations From 2015 to 2050. JAMA ophthalmology. 2016;134(7):802-809. 
30. UN. World Population Prospects: The 2017 Revision. In. https://esa.un.org/unpd/wpp/publications/files/wpp2017_keyfindings.pdf2017

31. Australian Bureau of Statistics. Life Tables for Aboriginal and Torres Strait Islander Australians, 2015-2017. 2018;

https://www.abs.gov.au/ausstats/abs@.nsf/Lookup/by\%20Subject/3302.0.55. 003 2015-

2017 Main\%20Features Life\%20expectancy\%20at\%20birth\%20of\%20Abori ginal\%20and\%20Torres\%20Strait\%20l slander\%20Australians 5 .

32. KeepSight. KeepSight. 2019; https://www.keepsight.org.au/.

33. Australian Government Department of Health. Budget 2016-2017: Portfolio budget statements 2016-2017; Budget-related paper No1.10. Health portfolio. Canberra2016.

34. Australian Government Department of Health. Implementation plan under the National Framework for Action to Promote Eye Health and Prevent Avoidable Blindness and Vision Loss. Canberra2014.

35. Australian Bureau of Statistics. National Health Survey: First results, 20172018 - Diabetes Mellitus. 2018;

https://www.abs.gov.au/ausstats/abs@.nsf/Lookup/by\%20Subject/4364.0.55. 001 2017-18 Main\%20Features Diabetes\%20mellitus 50. 
Table 1: Summary of the projected Australian population 50 years and older (Source Australian Bureau of Statistics).

\begin{tabular}{|c|c|c|c|c|c|c|c|c|}
\hline & \multirow{2}{*}{$\begin{array}{c}\begin{array}{c}\text { Population } \mathbf{n} \\
(\%)\end{array} \\
2016 \\
(\mathrm{~N}=7,937,132) \\
\end{array}$} & \multicolumn{7}{|c|}{ Projected population structure \% } \\
\hline & & $\begin{array}{c}2020 \\
(N= \\
8,669,433)\end{array}$ & $\begin{array}{c}\mathbf{2 0 2 5} \\
(\mathrm{N}= \\
9,519,502)\end{array}$ & $\begin{array}{c}2030 \\
(N= \\
10,221,691)\end{array}$ & $\begin{array}{c}2035 \\
(N= \\
11,045,845)\end{array}$ & $\begin{array}{c}\mathbf{2 0 4 0} \\
(\mathrm{N}= \\
11,898,021)\end{array}$ & $\begin{array}{c}\mathbf{2 0 4 5} \\
(\mathrm{N}= \\
12,764,968)\end{array}$ & $\begin{array}{c}2050 \\
(N= \\
13,601,180)\end{array}$ \\
\hline \multicolumn{9}{|l|}{ Sex } \\
\hline Female & $4,151,943(52.3)$ & 52.1 & 52.2 & 52.4 & 52.5 & 52.6 & 52.6 & 52.5 \\
\hline $\begin{array}{l}\text { Male } \\
\text { Age (years) }\end{array}$ & $3,785,189(47.7)$ & 47.9 & 47.8 & 47.6 & 47.5 & 47.4 & 47.4 & 47.5 \\
\hline $50-59$ & $2,970,930(37.4)$ & 35.8 & 33.7 & 32.2 & 31.9 & 33.3 & 33.5 & 33.1 \\
\hline $60-69$ & $2,481,423(31.3)$ & 30.7 & 30.5 & 29.3 & 28.0 & 26.7 & 26.6 & 28.0 \\
\hline $70-79$ & $1,537,901(19.4)$ & 21.5 & 22.8 & 23.3 & 23.5 & 22.6 & 21.8 & 21.0 \\
\hline $\begin{array}{l}\text { 80-89 } \\
\text { Remoteness } \\
\text { area }\end{array}$ & $946,878(11.9)$ & 12.0 & 13.0 & 15.2 & 16.6 & 17.5 & 18.0 & 17.8 \\
\hline
\end{tabular}




\begin{tabular}{lr|rrrrrrr} 
Major City & $5,283,071(66.6)$ & 67.3 & 67.7 & 68.3 & 69.2 & 70.1 & 71.0 & 71.8 \\
Regional & $2,510,665(31.6)$ & 30.9 & 30.5 & 30.0 & 29.2 & 28.4 & 27.5 & 26.7 \\
Remote & $143,396(1.8)$ & 1.8 & 1.7 & 1.7 & 1.6 & 1.6 & 1.5 & 1.5 \\
\hline
\end{tabular}


Table 2: Characteristics of non-Indigenous and Indigenous National Eye Health Survey participants aged 50 years and over

\begin{tabular}{|c|c|c|c|}
\hline & $\begin{array}{c}\text { Non- } \\
\text { I ndigenous } \\
(\mathrm{n}=3098)\end{array}$ & $\begin{array}{c}\text { Indigenous } \\
(\mathrm{n}=1155)\end{array}$ & $\begin{array}{c}\text { p- } \\
\text { value* }\end{array}$ \\
\hline \multicolumn{4}{|l|}{ Sex } \\
\hline Female & $\begin{array}{r}1661 \\
(53.6 \%) \\
1437\end{array}$ & 668 (57.8\%) & 0.014 \\
\hline Male & $(46.4 \%)$ & 487 (42.2\%) & \\
\hline \multicolumn{4}{|l|}{ Age-group } \\
\hline $50-59$ & $\begin{array}{r}814(26.3 \%) \\
1167\end{array}$ & $632(54.7 \%)$ & $<0.001$ \\
\hline $60-69$ & $(37.7 \%)$ & 362 (31.3\%) & \\
\hline $70-79$ & $762(24.6 \%)$ & $135(11.7 \%)$ & \\
\hline$\geq 80$ & 355 (11.5\%) & $26(2.3 \%)$ & \\
\hline \multicolumn{4}{|c|}{ Educational attainment } \\
\hline $\begin{array}{l}\text { Did not complete } \\
\text { secondary }\end{array}$ & $\begin{array}{r}1342 \\
(43.3 \%)\end{array}$ & 6) & \\
\hline Completed secondary & $481(15.5 \%)$ & $78(6.8 \%)$ & \\
\hline Completed & 1275 & & \\
\hline trade/university & $(41.2 \%)$ & $344(29.8)$ & \\
\hline \multicolumn{4}{|l|}{ Remoteness area } \\
\hline Major City & $\begin{array}{r}(40.4 \%) \\
1261\end{array}$ & $499(43.2 \%)$ & 0.080 \\
\hline Regional & $(40.7 \%)$ & $470(40.7 \%)$ & \\
\hline Remote & 584 (18.9\%) & $186(16.1 \%)$ & \\
\hline \multicolumn{4}{|l|}{ Place of birth } \\
\hline Oceania & $\begin{array}{r}2216 \\
(71.5 \%)\end{array}$ & & \\
\hline Europe & $655(21.1 \%)$ & & \\
\hline Others & $227(7.3 \%)$ & & \\
\hline \multicolumn{4}{|l|}{ Bilateral vision loss } \\
\hline No & $\begin{array}{r}2890 \\
(93.3 \%)\end{array}$ & $\begin{array}{r}1001 \\
(86.7 \%)\end{array}$ & $<0.001$ \\
\hline Yes & $208(6.7 \%)$ & $154(13.3 \%)$ & \\
\hline \multicolumn{4}{|l|}{ Cause } \\
\hline Refractive error & $124(4.0 \%)$ & 87 (7.5\%) & $<0.001$ \\
\hline
\end{tabular}


Cataract

$28(0.9 \%) \quad 38(3.3 \%)$

Other

$56(1.8 \%) \quad 29(2.5 \%)$

* Characterisitics compared between Indigenous and Non-

Indigenous participants using Pearson's $\chi^{2}$ test

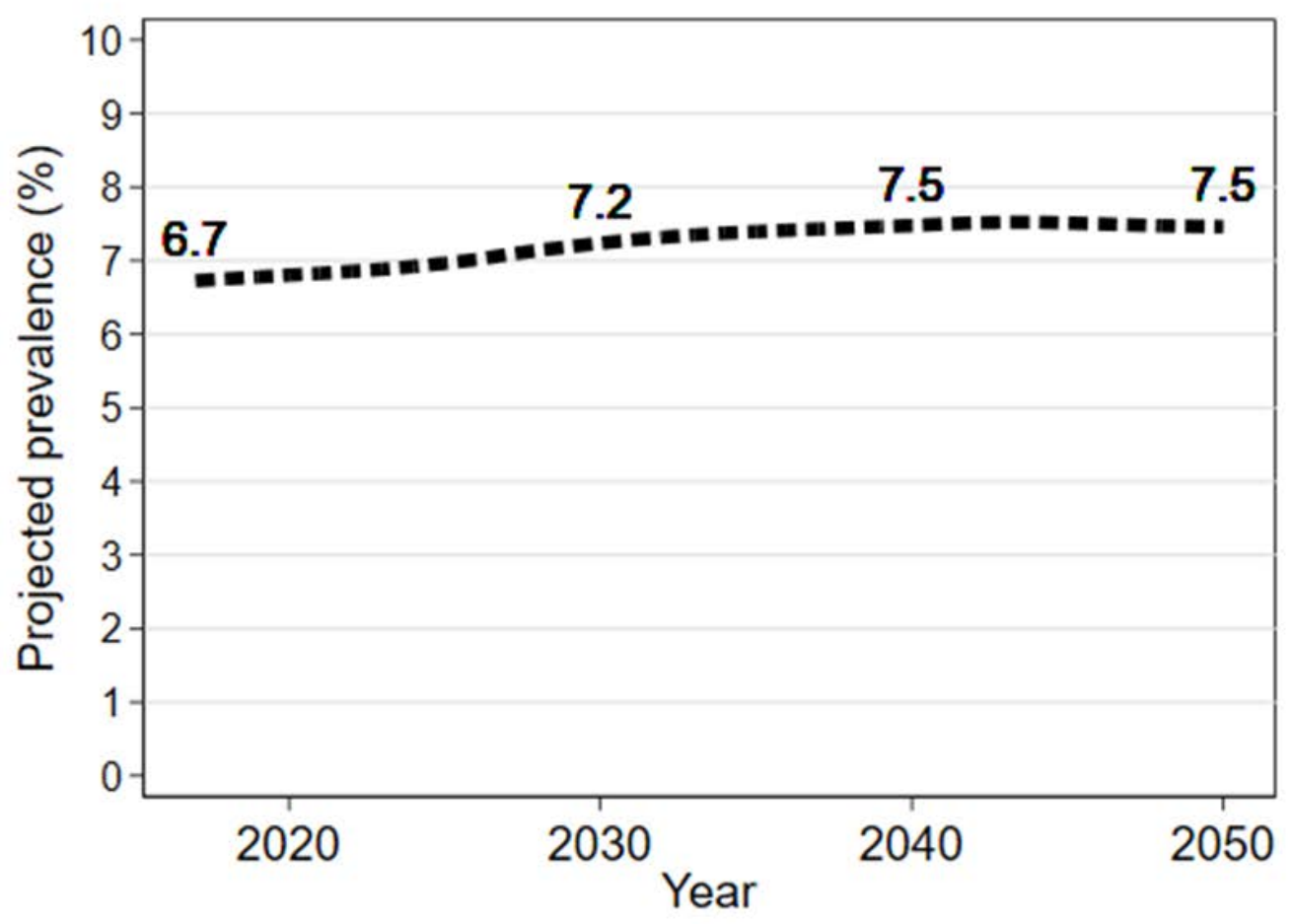

Figure 1: Projected prevalence of bilateral vision loss among Australians aged $\geq 50$ years from 2020 to 2050. 
Table 3: Projected number of Australian people with bilateral visual impairment by age and sex based on presenting visual acuity.

\begin{tabular}{|c|c|c|c|c|c|c|c|c|c|c|}
\hline & \multicolumn{3}{|c|}{$\begin{array}{l}2016 \text { estimates of bilateral visual } \\
\text { impairment }\end{array}$} & \multicolumn{7}{|c|}{ Projected number with bilateral visual impairment** } \\
\hline & $\begin{array}{c}\text { Population } \\
\text { sizet }\end{array}$ & $\begin{array}{l}\text { Prevalence } \\
\text { (\% )* }\end{array}$ & $\underset{*}{\text { Number* }}$ & 2020 & 2025 & 2030 & 2035 & 2040 & 2045 & 2050 \\
\hline \multicolumn{11}{|l|}{ Male } \\
\hline $50-59$ years & $1,516,841$ & 4.1 & 62,107 & 64,574 & 66,718 & 67,748 & 72,127 & 81,235 & 87,482 & 91,206 \\
\hline $60-69$ years & $1,271,712$ & 4.9 & 62,688 & 67,587 & $\begin{array}{l}73,751 \\
104,11\end{array}$ & $\begin{array}{l}76,431 \\
115,58\end{array}$ & $\begin{array}{l}79,231 \\
126,36\end{array}$ & $\begin{array}{l}80,738 \\
131,49\end{array}$ & $\begin{array}{l}86,397 \\
137,12\end{array}$ & 97,481 \\
\hline 70-79 years & 800,631 & 9.2 & 73,331 & 88,097 & 5 & $\begin{array}{r}8 \\
105,75\end{array}$ & $\begin{array}{r}9 \\
125.03\end{array}$ & $\begin{array}{r}6 \\
143,49\end{array}$ & $\begin{array}{r}9 \\
158,89\end{array}$ & 140,304 \\
\hline$\geq 80$ years & 562,759 & 12.2 & 68,709 & 73,725 & 85,233 & 5 & 8 & 1 & 5 & 168,698 \\
\hline Total $\geq 50$ years & $4,151,943$ & 6.4 & 266,835 & $\begin{array}{r}293,98 \\
2\end{array}$ & $\begin{array}{r}329,81 \\
7\end{array}$ & $\begin{array}{r}365,52 \\
2\end{array}$ & $\begin{array}{r}402,76 \\
4\end{array}$ & $\begin{array}{r}436,96 \\
0\end{array}$ & $\begin{array}{r}469,90 \\
3\end{array}$ & 497,689 \\
\hline \multicolumn{11}{|l|}{ Female } \\
\hline $50-59$ years & $1,454,089$ & 6.4 & 93,492 & 98,042 & $\begin{array}{r}101,70 \\
4\end{array}$ & $\begin{array}{r}105,12 \\
6\end{array}$ & $\begin{array}{r}113,07 \\
7\end{array}$ & $\begin{array}{r}126,70 \\
0\end{array}$ & $\begin{array}{r}137,66 \\
8\end{array}$ & 146,296 \\
\hline $60-69$ years & $1,209,711$ & 3.3 & 40,150 & 42,932 & 46,492 & 47,616 & 49,148 & 50,463 & $\begin{array}{l}53,955 \\
100,20\end{array}$ & 60,179 \\
\hline $70-79$ years & 737,270 & 7.6 & 56,379 & 68,990 & $\begin{array}{l}79,482 \\
105,47\end{array}$ & $\begin{array}{l}86,270 \\
135,29\end{array}$ & $\begin{array}{l}93,856 \\
157,96\end{array}$ & $\begin{array}{l}96,492 \\
179,02\end{array}$ & $\begin{array}{r}8 \\
197,24\end{array}$ & 103,259 \\
\hline$\geq 80$ years & 384,119 & 19.7 & 75,530 & 85,943 & 8 & 4 & 1 & 1 & 3 & 207,598 \\
\hline Total $\geq 50$ years & $3,785,189$ & 7.0 & 265,551 & $\begin{array}{r}295,90 \\
7\end{array}$ & $\begin{array}{r}333,15 \\
6\end{array}$ & $\begin{array}{r}374,30 \\
6\end{array}$ & $\begin{array}{r}414,04 \\
1\end{array}$ & $\begin{array}{r}452,67 \\
6\end{array}$ & $\begin{array}{r}489,07 \\
4\end{array}$ & 517,332 \\
\hline \multicolumn{11}{|l|}{$\begin{array}{l}\text { Male and } \\
\text { female }\end{array}$} \\
\hline $50-59$ years & $2,970,930$ & 5.2 & 155,599 & $\begin{array}{r}162,61 \\
6\end{array}$ & $\begin{array}{r}168,42 \\
2\end{array}$ & $\begin{array}{r}172,87 \\
4\end{array}$ & $\begin{array}{r}185,20 \\
3\end{array}$ & $\begin{array}{r}207,93 \\
5\end{array}$ & $\begin{array}{r}225,15 \\
0\end{array}$ & 237,502 \\
\hline
\end{tabular}




\begin{tabular}{|c|c|c|c|c|c|c|c|c|c|c|}
\hline & & & & 110,51 & 120,24 & 124,04 & 128,37 & 131,20 & 140,35 & \\
\hline \multirow{2}{*}{$60-69$ years } & $2,481,423$ & 4.1 & 102,838 & 9 & 3 & 7 & 9 & 1 & 2 & 157,660 \\
\hline & & & & 157,08 & 183,59 & 201,85 & 220,22 & 227,98 & 237,33 & \\
\hline \multirow[t]{2}{*}{$70-79$ years } & $1,537,901$ & 8.4 & 129,709 & 7 & 7 & 8 & 5 & 8 & 7 & 243,563 \\
\hline & & & & 159,66 & 190,71 & 241,04 & 282,99 & 322,51 & 356,13 & \\
\hline \multirow[t]{2}{*}{$\geq 80$ years } & 946,878 & 15.2 & 144,240 & 8 & 1 & 9 & 8 & 2 & 8 & 376,296 \\
\hline & & & & 589,89 & 662,97 & 739,82 & 816,80 & 889,63 & 958,97 & $1,015,02$ \\
\hline$\geq 50$ years & $7,937,132$ & 6.7 & 532,386 & 0 & 3 & 8 & 6 & 6 & 7 & 1 \\
\hline
\end{tabular}

† Source: Australian Bureau of Statistics.

* Weighted prevalence estimated via post-stratification according to the age, sex, remoteness area and Indigenous status 2016 population in addition to sample weighting according to study site.

** Estimated number of cases rounded to the nearest person which may result in the combined total being different to the sum of the listed estimates.

Table 4: Projected number of Australian people 50 years and older with bilateral visual impairment (based on presenting visual acuity), stratified by cause.

\begin{tabular}{|c|c|c|c|c|c|c|c|c|c|}
\hline \multirow[b]{2}{*}{ Cause } & \multicolumn{2}{|c|}{2016 estimates } & \multicolumn{7}{|c|}{ Projected number with bilateral visual impairment } \\
\hline & $\begin{array}{c}\text { Prevalence } \\
(\%)^{*}\end{array}$ & $\underset{r}{\text { Numbe }}$ & 2020 & 2025 & 2030 & 2035 & 2040 & 2045 & 2050 \\
\hline Uncorrected refractive error & 4.2 & 331,914 & 363,715 & 400,139 & 432,108 & 468,844 & 507,788 & 545,521 & 578,969 \\
\hline Cataract & 0.9 & 69,327 & 78,149 & 90,363 & 104,293 & 116,967 & 127,121 & 136,808 & 144,014 \\
\hline Other^ & 1.7 & 131,145 & 148,026 & 172,471 & 203,427 & 230,995 & 254,727 & 276,648 & 292,037 \\
\hline
\end{tabular}

This article is protected by copyright. All rights reserved. 
* Weighted prevalence estimated via post-stratification according to the age, sex, remoteness area and Indigenous status of the 2016 population in addition to sample weighting according to study site. Based on presenting visual acuity.

^Other: all conditions causing vision loss other than uncorrected refractive error and cataract 


\section{University Library}

\section{- M M N E R VA A gateway to Melbourne's research publications}

Minerva Access is the Institutional Repository of The University of Melbourne

Author/s:

Foreman, J;Keel, S;McGuiness, M;Liew, D;Franzco, PVW;Franzco, HRT;Dirani, M

Title:

Future burden of vision loss in Australia: Projections from the National Eye Health Survey

Date:

2020-05-18

Citation:

Foreman, J., Keel, S., McGuiness, M., Liew, D., Franzco, P. V. W., Franzco, H. R. T. \& Dirani, M. (2020). Future burden of vision loss in Australia: Projections from the National Eye Health Survey. CLINICAL AND EXPERIMENTAL OPHTHALMOLOGY, 48 (6), pp.730-738. https:// doi.org/10.1111/ceo.13776.

Persistent Link:

http://hdl.handle.net/11343/275764 